Proc. Indian Acad. Sci., Vol. 88 A, Part 1, Number 1, February 1979, pp. 33-41. (a) printed in India.

\title{
Electrochemical reduction of $\mathrm{Cu}(\mathrm{II})$-EDTA complex at dropping mercury electrode. An impedance approach
}

\author{
G A BHAT \\ Department of Organic Chemistry, Indian Institute of Science, Bangalore 560012
}

MS received 2 September 1978

\begin{abstract}
The study of electrochemical reduction of $\mathrm{Cu}(\mathrm{II})$-EDTA system by phase sensitive a.c. impedance method at dropping mercury electrode reveals several interesting features. The complex plane polarograms exhibit loop like shape in contrast to the classical zinc ion reduction where crest like shape is found. Again, the relative placement of peaks of in-phase and quadrature components, and the relative placement of portions before and after the peaks of complex plane polarograms are different from that of zinc ion reduction. The complex plane plots suggest that electrochemical reduction of Cu-EDTA is charge transfer controlled.
\end{abstract}

Keywords. Electrochemical reduction; Cu-EDTA system; impedance method; complex plane polarography.

\section{Introduction}

Randles' publication (Randles 1947) on electrode' kinetics to understand the electrochemical reactions in terms of electrical equivalents gave rise to considerable activities in this area. Interesting observations were made on a variety of electrochemical systems and were interpreted on the basis of modified Randles' equivalent circuits (Laitinen and Randles 1955; Senda and Delahay 1960). Among the theoretical developments of recent years analysis of impedance data for electrochemical systems by Sluyters and coworkers is noteworthy and this subsequently led to a new method called complex impedance plane analysis (Sluyters-Rehbach and Sluyters 1963). This method has been proved to be an excellent tcol to study several types of electrochemical reactions in electrode kinetics of inorganic salts, metal complexes (Verkroost et al 1972; Kisova et al 1972), organic compounds * (Bhat and Subrahmanya 1978), in studies on membranes (De Levie et al 1975) and batteries (Euler 1972) and in electrochemistry of solids (Armstrong et al 1978). Such studies led to new concepts like negative impedance (Tanaka and Tamamushi 1963; De Levie and Husovsky 1969) and demonstrated the existence of peculiar types of complex plane patterns. The present work deals with the analysis of impedance data obtained by phase-sensitive a.c. polarographic technique and presents a new type of complex plane patterns. 


\section{Experimental}

The measurements of cell impedance, experimental conditions and the method of analysis were described in a previous communication (Bhat 1976a). The calculation was programmed on an IBM-360/44 computer. The stock solution of Cu-EDTA complex was prepared by mixing equimolar solutions of disodium salts of EDTA and $\mathrm{CuCl}_{2}$ (Furness et al 1949). The solution was tested for free copper ion polarographically and no trace of it was found in the solution. All solutions were prepared in double distilled water and all chemicals used were of analytical grade.

\section{Results and discussion}

\subsection{Complex impedance plane plots at a fixed frequency and at a varying potential}

The electrochemical reaction considered here is of the type,

$$
O x+n e \rightleftharpoons R
$$

and corresponds to the Randles' equivalent circuit (figure 5b). From the recorded in-phase and quadrature components (figure 1) the cell impedance was calculated on the basis of this equivalent circuit. The real $\left(R_{8}\right)$ and imaginary $\left(\omega C_{8}\right)^{-1}$ components of the cell impedance were plotted on a complex plane as a function of potential keeping the frequency constant (figure 2). These are referred to as complex plane polarograms. The important features of these polarograms are summarised below.

The nature of the complex plane polarograms could be divided broadly into two groups depending on the frequency of the measurements. At low frequencies complex plane polarograms exhibit well defined peaks (figure 2) and potentials where such peaks occur would correspond to the potentials of maximum of inphase components. The absolute values of real and imaginary components are relatively high and decrease with increase in frequency. The descending and ascending branches (parts of polarograms at potentials before and after the peak respectively) as shown by the arrows are quite steep. These two branches cross each other at some point forming a loop-like shape. The existence of such a point on each of the polarograms indicates that the same impedance values are obtained at two different potentials though they differ by approximately $0.5 \mathrm{~V}$. At high frequencies, however, the complex plane polarograms do not exhibit any sharp peaks, instead they form a broad curve. The absolute values of real and imaginary values are small.

There are a number of interesting features of these complex plane polarograms. The relative positions of the curve before and after the peak are one of the features. In this system the ascending branches lie lower to that of descending branches at all frequencies. This behaviour is different from that of Cu-CyDTA complex (Bhat 1978), where such a behaviour is found only at lower frequencies. The loops are formed by complex plane polarograms in this system at all frequencies whereas in Cu-CyDTA complex it exists only at lower frequencies. In comparison with complex plane polarograms of electrochemical reduction of zinc ion, 


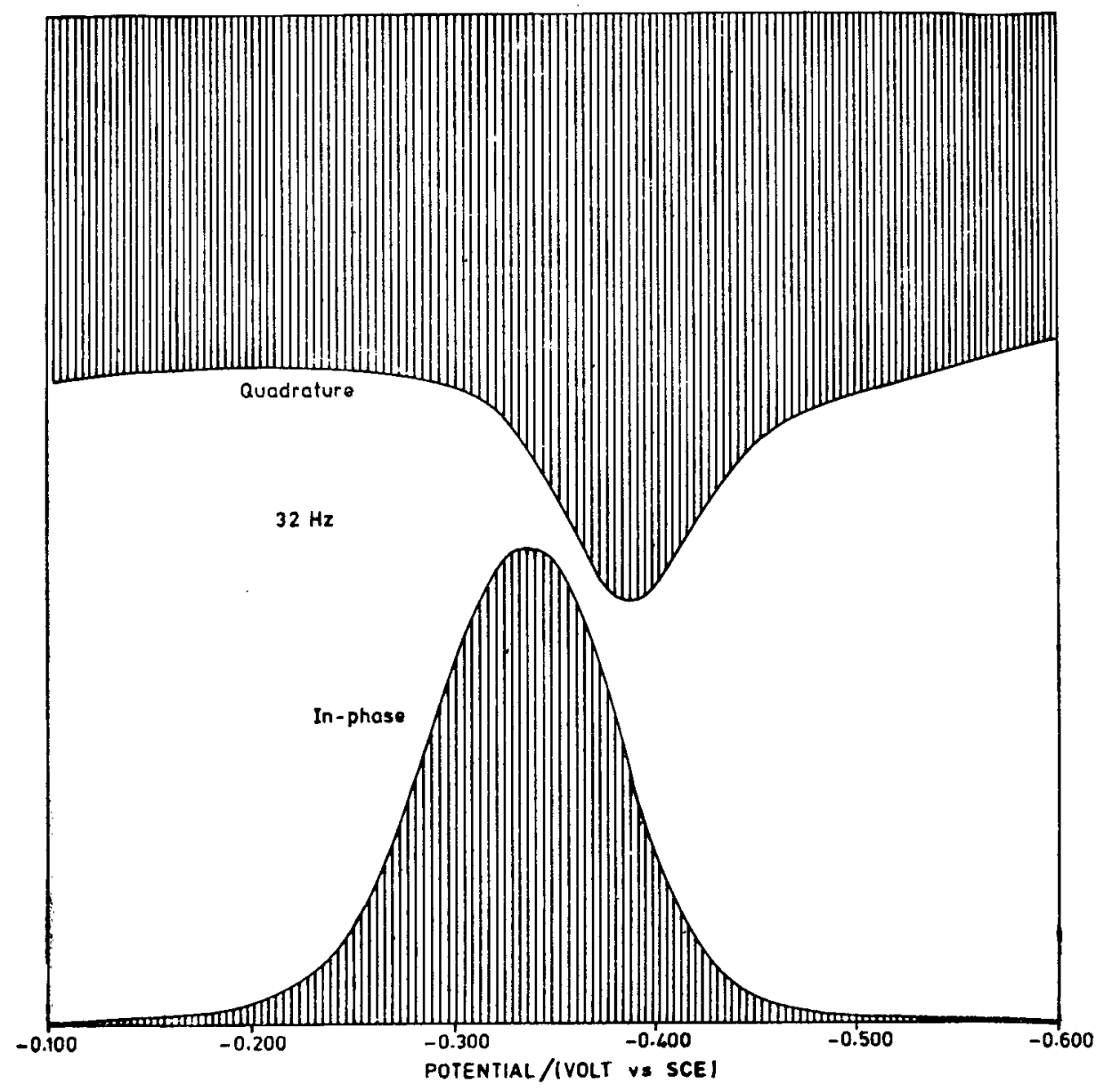

Figure 1. A typical in-phase and quadrature components recorded at $32 \mathrm{~Hz}$. Cu-EDTA $-2.0 \mathrm{mM}$; acetate buffer $-0.1 \mathrm{M}$; . $\mathrm{KNO}_{3}-0.4 \mathrm{M}$; polyoxyethylene lauryl ether (LEO) $-3 \cdot 0 \mu \mathrm{M}$. Potentials are with respect to SCE.

it can be said that this system behaves differently. In the former case, there is no loop formation (Sluyters-Rehbach and Sluyters 1970) instead they show a crestlike structure. The ascending and descending branches do not cross each other at any potential. Also, the ascending branches lie above the descending branches. The peculiar behaviour of complex plane polarograms of Cu-EDTA complex is probably due to the potential dependency of double layer capacitance (Sluyters 1978). The detailed theory and explanations are being worked out and will be published later.

3.2. Complex impedance plane plots at a fixed potential and at varying frequency

At a single potential in the neighbourhood of the peak of complex plane polaro. grams the in-phase and quadrature components are analysed at various frequencies ranging from $28 \mathrm{~Hz}$ to $2000 \mathrm{~Hz}$ to obtain the real and imaginary components. 


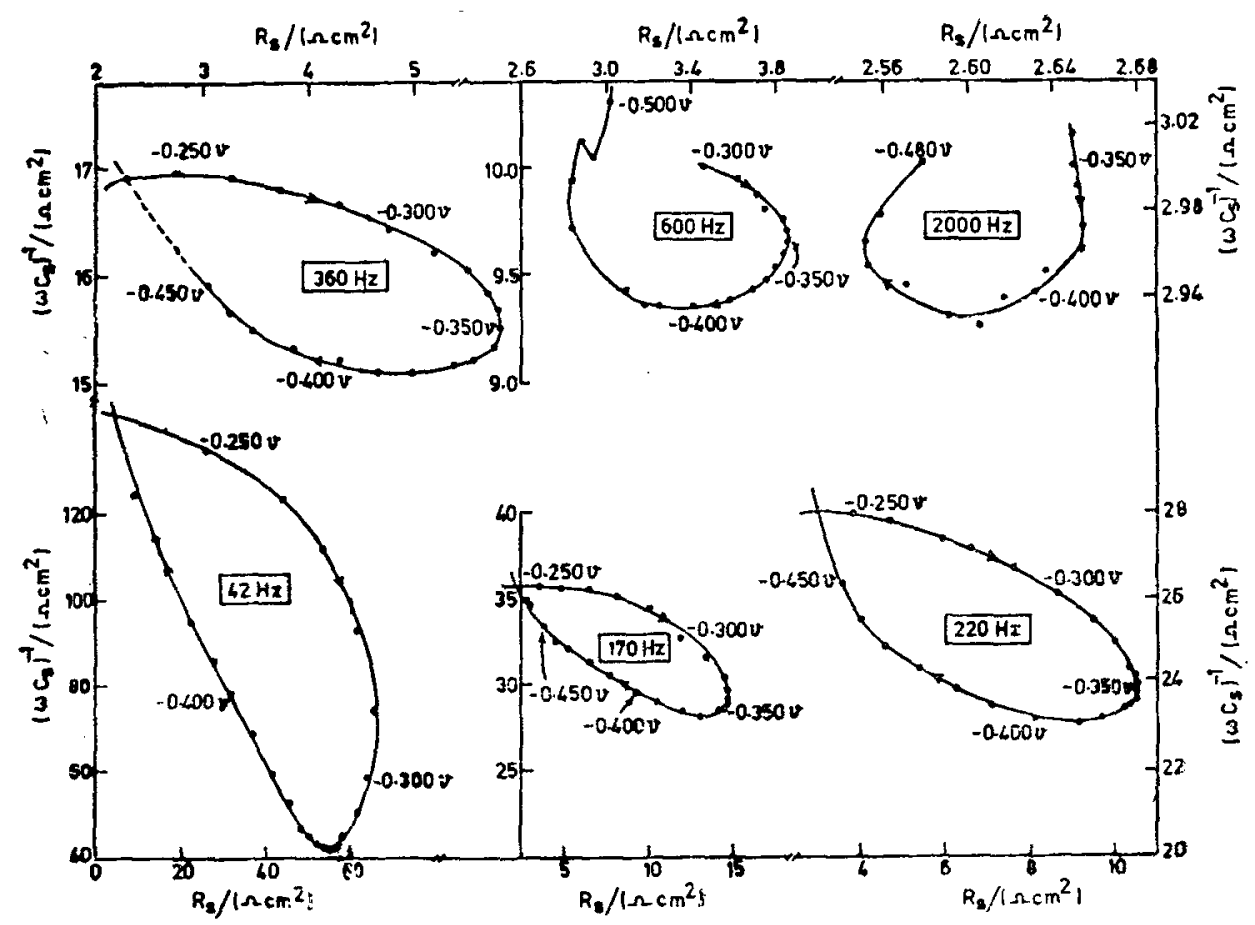

Figure 2. Complex plane polarograms. Plots of $\left(\omega \mathrm{C}_{8}\right)^{-1}$ vs. $\mathbf{R}_{8}$ at a fixed frequency and varying potential. The direction of arrow indicates the cathodic increase of potential applied. Experimental conditions are same as in figure 1.

These are plotted on a complex impedance plane as a function of frequency (figures 3 and 4). The locus of these points form semicircles at bigher frequencies. However, at low frequencies the points deviate from the semicircles owing to diffusion polarisation. The well defined semicircles in figures 3 and 4 suggest that the electrochemical reduction of $\mathrm{Cu}$-EDTA complex is charge-transfer controlled. The theoretical explanations for the occurrence of semicircles are given by Sluyters and is governed by the eq. (1) (Sluyters-Rehbach and Sluyters 1963)

$$
\left(R_{s}-R_{\Omega}-\frac{\theta}{2}\right)^{2}+\left[\left(\omega C_{s}\right)^{-1}\right]^{2}=\frac{\theta^{2}}{4}
$$

where $R_{\varepsilon}$ is the series resistance, $R_{\Omega}$ is the ohmic resistance of the cell, $C_{8}$ is the series capacitance, $\theta$ is the charge-transfer resistance, $\omega=2 \pi f, f$ is the frequency in $\mathrm{Hz}$. According to eq. (1), the diameter of the semicircle should give the value of charge-transfer resistance. The charge-transfer resistance has been obtained at several potentials near about the peak of the complex plane polarograms and are plotted as a function of potential (figure 5a). This curve is hyperbolic in nature and has a minimum at $-0.340 \mathrm{~V}$. At far negative potentials semicircles are not well defined (figure 4, curve IV) and introduce an error in measurements of $\theta$. The hyperbolic curve suggests that the charge-transfer resistance will increase very much at potentials far away from the minimum. 


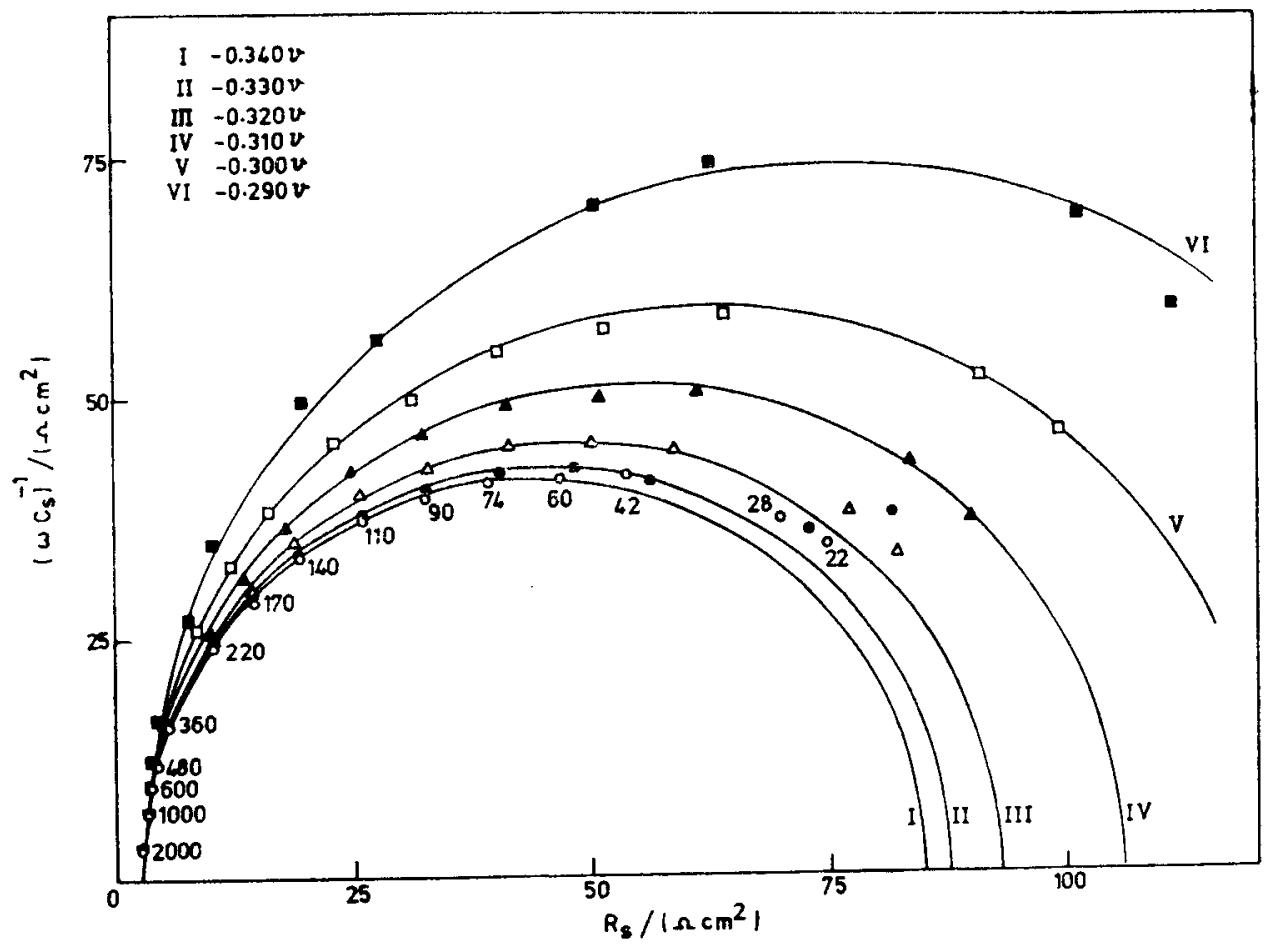

Figure 3. Complex plane plots at fixed potentials before peak as a function of frequency. Experimental conditions are same as in figure 1.

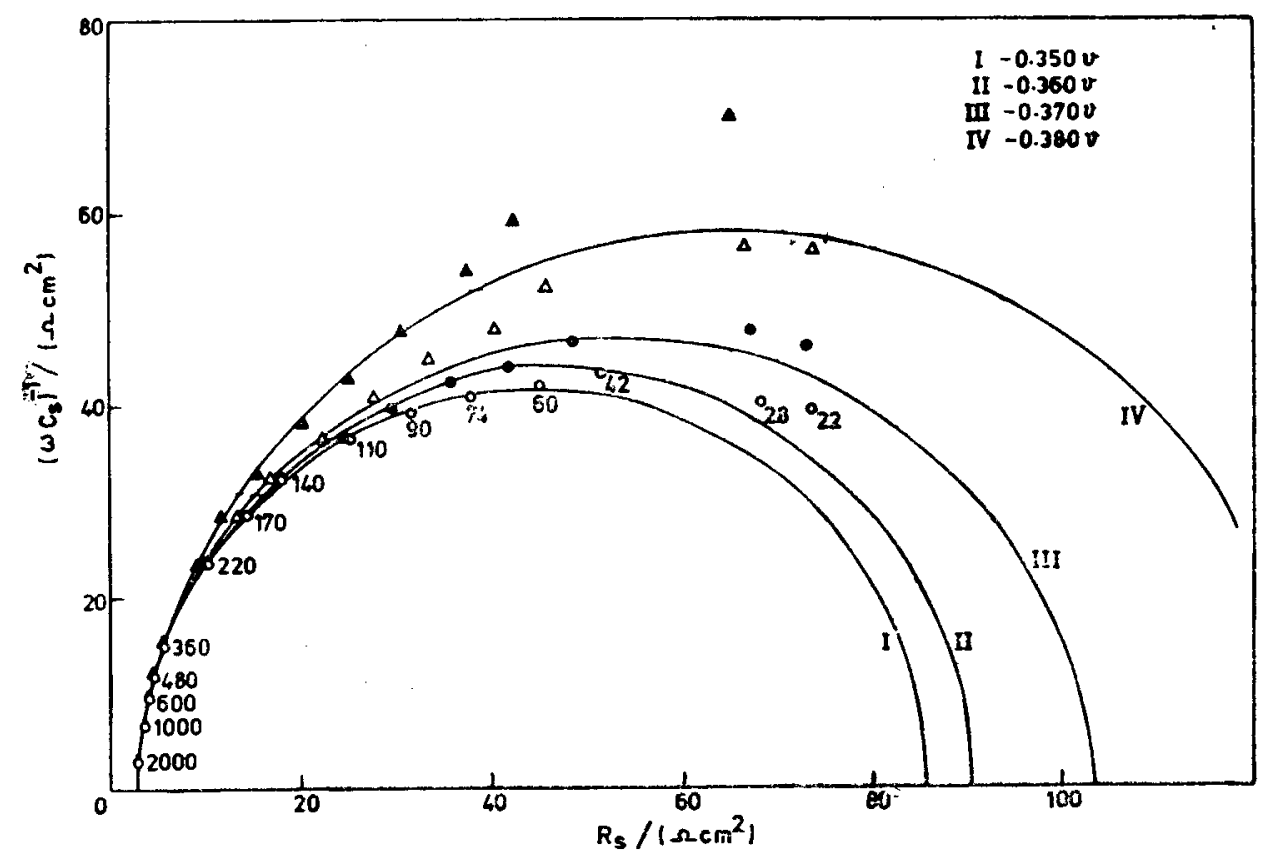

Figure 4. Complex plane plots at fixed potentials after the peak as a function of frequency. Experimental conditions are same as in figure 1 , 
(a)

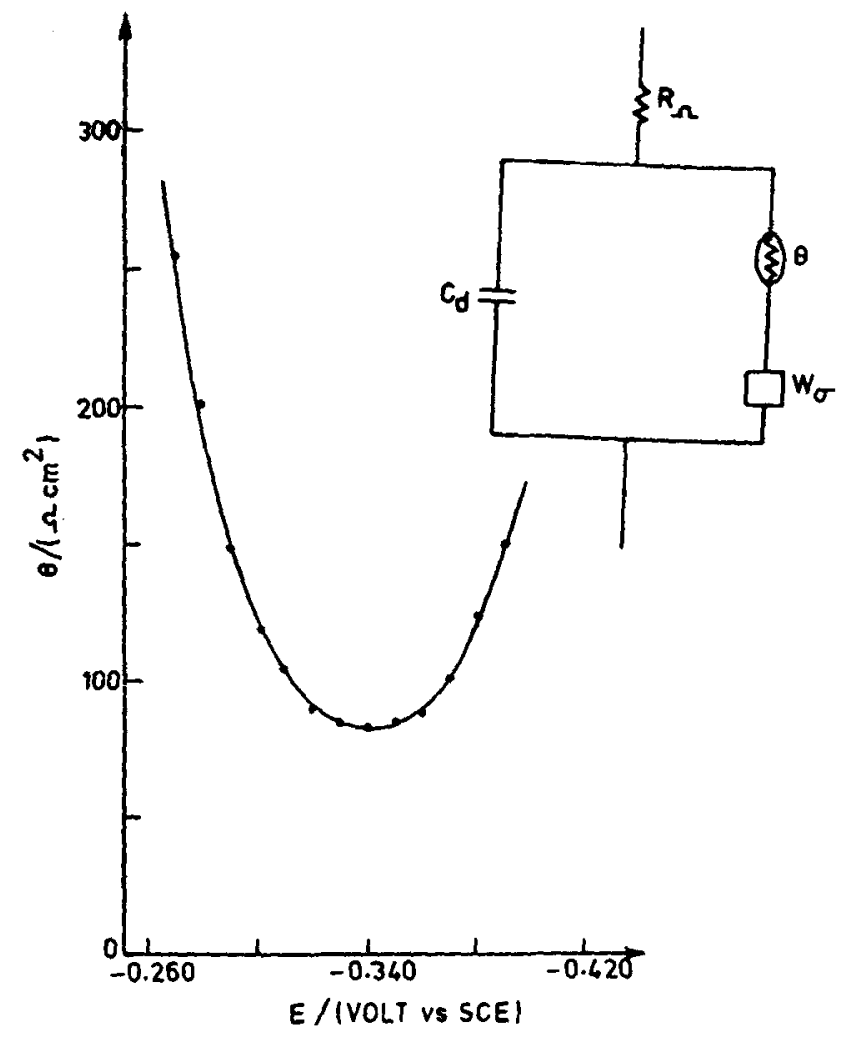

(b)

Figure 5. (a) Variation of charge-transfer resistance as a function of potential. Experimental conditions are same as in figure 1. (b) Randles' equivalent circuit. $\mathrm{R}_{\Omega}$-Ohmic resistance; $\mathrm{C}_{d}$-double layer capacitance; $\theta$-charge transfer resistance; $\mathrm{W}_{\sigma}$-Warburg impedance.

The evaluation of the standard rate constant for quasi-reversible reactions requires the use of complicated expression and needs lot of computation (SluytersRehbach and Sluyters 1970). However, an approximate value of the rate constant can be calculated using the expression derived for d.c. reversible case using the minimum value of $\theta$. Such an expression is given below:

$$
k_{\mathrm{z}}=\frac{R T}{n^{2} F^{2} \theta_{\min } C} \times \frac{d^{1(1-a)}}{a^{a}(1-a)^{(1-a)}}
$$

where $k_{s}$ is the standard rate constant, $C$ is the concentration of the depolariser, $d=D_{\mathrm{R}} / D_{\mathrm{o}} ; D_{\mathrm{R}}$ and $D_{\mathrm{o}}$ are diffusion coefficients of the reduced and oxidised species respectively, $a$ is the cathodic transfer coefficient, $R, T, n$ and $F$ have their usual meaning. The value of $a$ is taken as 0.53 (Bhat 1976b). The $\theta$ value at minimum potential is $147 \Omega \mathrm{cm}^{2}$. mole/cc and the standard rate constant calculated is $0.85 \times 10^{-3} \mathrm{~cm}$. $\mathrm{sec}^{-1}$. The intercept on $R_{8}$ axis at infinite frequency is $R_{\Omega}=2.63 \Omega \mathrm{cm}^{2}$ and is in good agreement with $R_{\Omega}=2.68 \Omega \mathrm{cm}^{2}$, obtained from the blank solution, 
Unlike in the reversible system, the maxima of in-phase and quadrature components of this system do not lie at the same potential. Also, the maxima of both components shift to more negative potentials with increase in frequency. This shift is due to irreversible nature of the system and can be explained on the basis of the formula derived for irreversible processes (Sluyters' personal communication)

$$
E_{p}-E_{1}=-\frac{R T}{a n F} \ln (6 \pi \omega t / 7)^{4}
$$

where $E_{p}$ is the peak potential, $E_{\frac{1}{2}}$ is the half-wave potential of the d.c. polarogram (figure 6), $t$ is the drop time of the mercury drop and other terms have their usual meaning. It is interesting to note from formula (3) that the half-wave potential and peak potential do not coincide due to irreversibility as shown in figure 6 . Also, it is obvious from (3) that $E_{p}$ should vary with frequency as other terms are constants, explaining thereby the shift of the peak potentials with increase in frequency (table 1).

A comparison of in-phase and quadrature components of this system with that of zinc ion reduction reveals another interesting point. In this system the peak potentials of in-phase components are less negative than the peak potentials of quadrature components at all frequencies whereas the reverse is true for zinc ion reduction. The factors that would influence the occurrence of peaks for inphase and quadrature components are not known at present. Probably, the relative values of charge-transfer resistance, double layer capacitance and Warburg

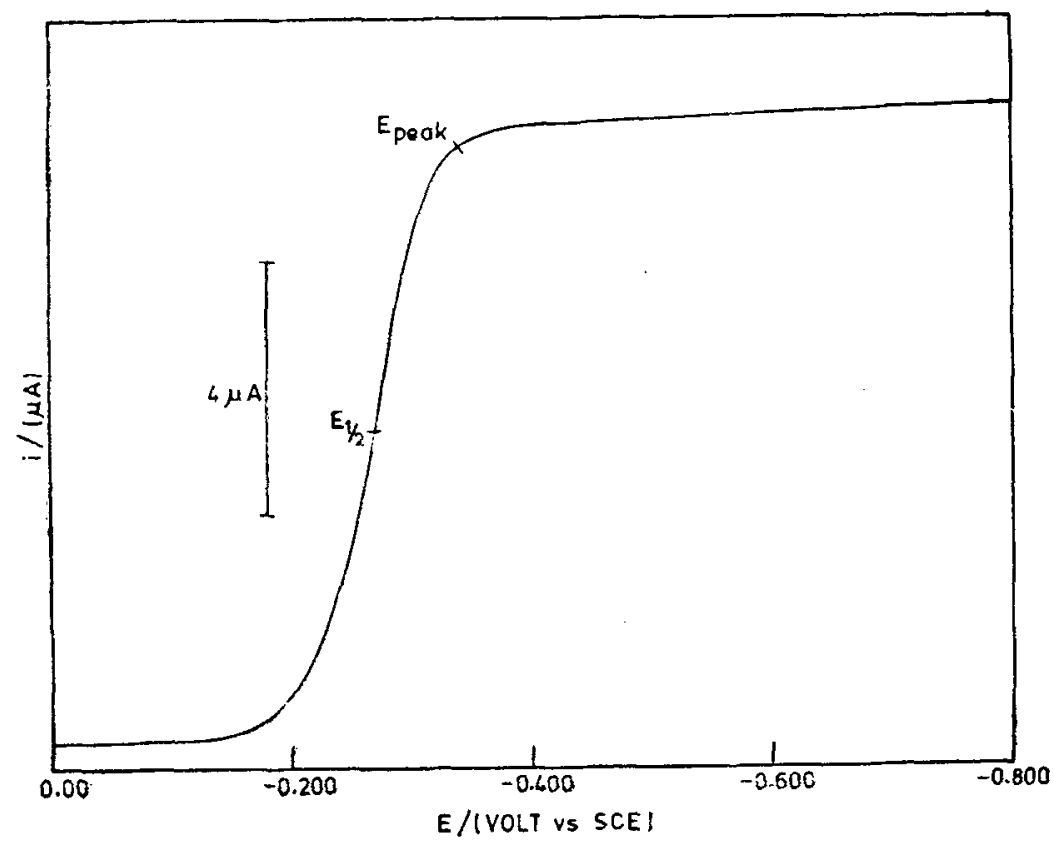

Figure 6. DC polarogram. Experimental conditions are same as in figure 1. 
Table 1. The shift of peak potentials of in-phase and quadrature components with varying frequency. All potentials refer with respect to SCE. The accuracy of measurements of potentials is \pm 0.003 volt.

\begin{tabular}{ccc}
\hline $\begin{array}{c}\text { Frequency } \\
\text { (Hz) }\end{array}$ & $\begin{array}{c}-E_{\text {peak }} \text { (volt) } \\
\text { (in-phase) }\end{array}$ & $\begin{array}{c}-E_{\text {peak }} \text { (volt) } \\
\text { (quadrature) }\end{array}$ \\
\hline & & \\
22 & 0.335 & 0.380 \\
38 & 0.340 & 0.385 \\
35 & 0.343 & 0.385 \\
42 & 0.343 & 0.385 \\
60 & 0.343 & 0.390 \\
74 & 0.345 & 0.393 \\
90 & 0.347 & 0.395 \\
110 & 0.350 & 0.400 \\
140 & 0.350 & 0.400 \\
170 & 0.350 & 0.405 \\
220 & 0.355 & 0.410 \\
280 & 0.358 & 0.415 \\
360 & 0.360 & 0.425 \\
480 & 0.365 & 0.425 \\
600 & 0.365 & 0.430 \\
1000 & 0.390 & \\
1400 & 0.405 & 0.465 \\
& & \\
\hline
\end{tabular}

impedance may decide together the positions of peaks. A theoretical modelling of the in-phase and quadrature components would, perhaps, throw some light on it.

\section{Acknowledgements}

The author is grateful to Dr R Tamamushi, Chief of Laboratory, The Institute of Physical and Chemical Research, Wakoshi, Saitama, Japan, for having provided the facility to carry out this work and also for the helpful discussions with him. The financial assistance by Japan Society for the Promotion of Science is gratefully acknowledged. The author would like to thank Dr M L Gopikanth for having written the programme for computation.

\section{References}

Armstrong R D, Bell M F and Metcalfe A A 1978 Electrochemistry ed. H R Thirsk (Chemical Society Specialist Periodical Reports) Vol. 6 Ch. 3

Bhat G A 1976a J. Electrochem. Soc. India 25127

Bhat G A 1976b Bull. Chem. Soc. Jpn. 492855

Bhat G A 1978 Proc. Indian Acad. Sci. 87A 447

Bhat G A and Subrahmanya R S 1978 (Submitted)

De Levie R and Husovsky A A $1969 J$. Electroanal. Chem. 2229

De Levie R, Thomas J W and Abbey K M 1975 J. Electroanal. Chem. 62111 
De Levie R and Vukadin D 1975 J. Electroanal. Chem. 6295

Euler K J 1972 Electrochim. Acta 17619

Furness W, Crawshaw P and Cule Davis 1949 Analyst 74629

Kisova L, Sluyters-Rehbach M and Sluyters J H 1972 J. Electroanal. Chem. 4029

Laitenen H A and Randles J E B 1955 Trans. Faraday Soc. 5154

Randles J E B 1947 Disc. Faraday Soc. 111

Senda M and Delahay P 1960 J. Phys. Chem. 651580

Sluyters J H 1978 Personal Communication

Sluyters-Rehbach M and Sluyters J H 1963 Rec. Trav. Chim. 82 525, 531

Sluyters-Rehbach M and Sluyters J H 1970 Electroanalytical Chemistry ed. A J Bard (Marcel Dekker) Vol. 4 Ch. 1

Tanaka N and Tamamushi R 1963 Proc. Aust. Conf. Electrochem. p 248

Verkroost A W M, Sluyters-Rehbach M and Sluyters J H 1972 J. Electroanal. Chem. 39147 